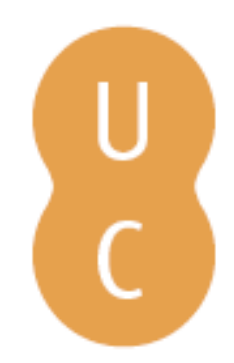

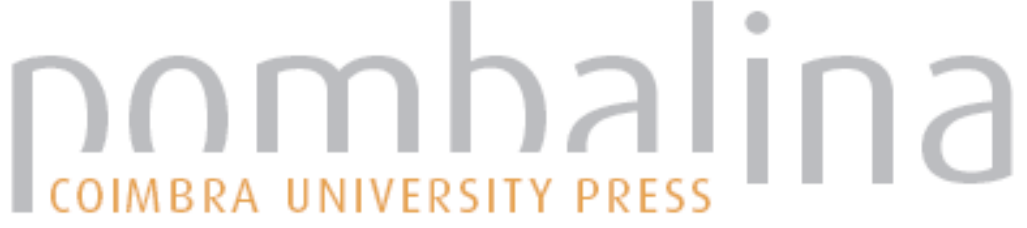

\section{A herança dos descobrimentos: rotas de ciência e beleza}

Autor(es): $\quad$ Cunha, Fanny Andrée Font Xavier da

Publicado por: Imprensa da Universidade de Coimbra

URL

persistente: URI:http://hdl.handle.net/10316.2/32441

DOI: $\quad$ DOI:http://dx.doi.org/10.14195/978-989-26-0469-5_32

Accessed : $\quad$ 26-Apr-2023 14:13:51

A navegação consulta e descarregamento dos títulos inseridos nas Bibliotecas Digitais UC Digitalis, UC Pombalina e UC Impactum, pressupõem a aceitação plena e sem reservas dos Termos e Condições de Uso destas Bibliotecas Digitais, disponíveis em https://digitalis.uc.pt/pt-pt/termos.

Conforme exposto nos referidos Termos e Condições de Uso, o descarregamento de títulos de acesso restrito requer uma licença válida de autorização devendo o utilizador aceder ao(s) documento(s) a partir de um endereço de IP da instituição detentora da supramencionada licença.

Ao utilizador é apenas permitido o descarregamento para uso pessoal, pelo que o emprego do(s) título(s) descarregado(s) para outro fim, designadamente comercial, carece de autorização do respetivo autor ou editor da obra.

Na medida em que todas as obras da UC Digitalis se encontram protegidas pelo Código do Direito de Autor e Direitos Conexos e demais legislação aplicável, toda a cópia, parcial ou total, deste documento, nos casos em que é legalmente admitida, deverá conter ou fazer-se acompanhar por este aviso.

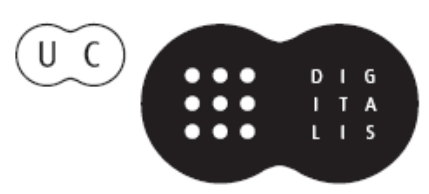


Ana Leunar Pereira João Rui Pita

[ Coordenaçä̃ ]
Rotas da Natureza

Cientistas

Viagens

Expedifgũes

Instituip̧ües

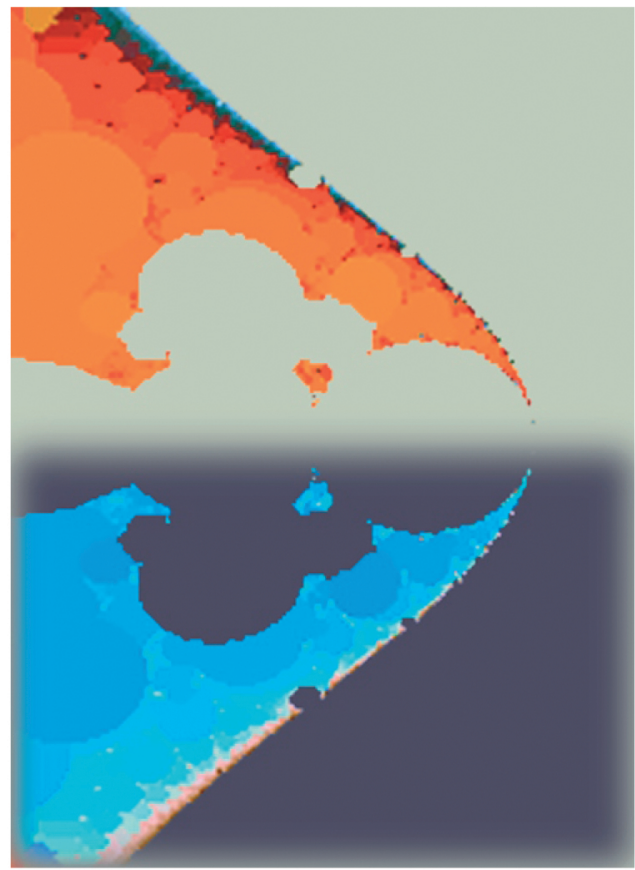




\section{Coordenaçáo Científica da Colecção Ciências e Culturas}

João Rui Pita e Ana Leonor Pereira

Os originais enviados são sujeitos a apreciação científica por referees

\section{Coordenação Editorial}

Maria João Padez Ferreira de Castro

\section{Edição}

Imprensa da Universidade de Coimbra

Email:impresauc@ci.uc.pt

URL: http://www.imp.uc.pt • Normas de publicação de colecçôes

\section{Design}

António Barros

Pré-Impressáo

António Resende

Imprensa da Universidade de Coimbra

\section{Capa}

António Barros, com imagem de E. M. de Melo e Castro, 2003 [Fractal original gerado no Fractint com tratamento no Photoshop 7.0]; Cortesia: António Barros

Impressão e Acabamento

SerSilito • Maia

\section{ISBN}

978-989-8074-12-6

\section{Depósito Legal}

Obra publicada com a colaboraçáo de:
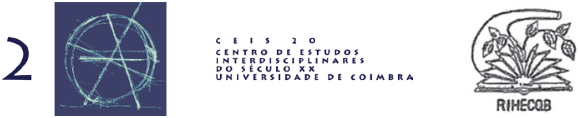

Obra publicada com o apoio de:

FCT Fundação para a Ciência e a Tecnologia

MINISTÉRIO DA CIÊNCIA, TECNOLOGIA E ENSINO SUPERTOR Portug

Programa Operacional Ciência, Tecnologia, Inovação do Quadro Comunitário de Apoio III
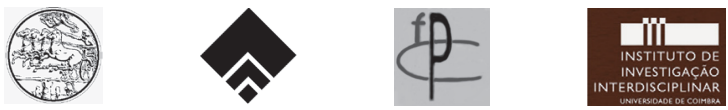

\section{Baxter}

(c) 2006, Imprensa da Universidade de Coimbra 
João Rui Pita

Ana Leonar Pereira

(Courdenação)

Rotas da Natureza

Cientistas

Viagens

Expediçũes

Instituiç̃̃es

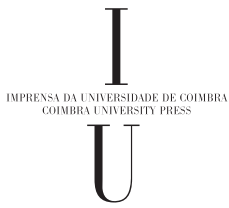

- colmbra 2006 
(Página deixada propositadamente em branco) 
Fanny Andrée Font Xavier da Cunha

Museu Nacional da Ciência e da Técnica de Coimbra, Portugal

A herança dos descobrimentos - rotas de CiênCIA E BELEZA

De todos os tempos os navegadores, os cronistas, os naturalistas, os boticários e os médicos portugueses contribuiram para o desenvolvimento das Ciências, sobretudo médicas e ciências subsidiárias. Mesmo fora das escolas médicas houve numerosos «curiosos»da Natureza, os quais foram os precursores da Biologia e da Medicina modernas. No ano de 1494 o Papa Alexandre VI, sugeriu que se dividisse o mundo ainda por descobrir entre Espanha e Portugal, as duas potências marítimas dominantes da época. A linha divisória estabelecida através do Atlântico, depois de os dois países terem chegado a um acôrdo sobre o seu traçado, atribuía para o ocidente da linha as terras inexploradas a Espanha, e para oriente a Portugal.

A cobiçada zona das especiarias ficava inteiramente na zona da expansão portuguesa, enquanto que a costa do Brasil também se encontrava na metade portuguesa.

Da cobiçada zona das especiarias, um escritor, António Galvão, viajante científico escreveu "Tratado dos vários e diversos caminhos, por onde nos tempos passados a pimenta e a especiaria veio da Índia às nossas partes, e assim de todos os descobrimentos antigos e modernos, que são feitos até à era de 1550, com os nomes particulares das pessoas que os fizerão, em que tempos, e suas alturas (1563)».

Assim foram criadas verdadeiras Rotas da Natureza que vieram a influir na construção científica do Mundo. Os Espanhois e os Portugueses foram os primeiros viajantes europeus a adquirir e a transmitir vastos conhecimentos sobre as doenças, os animais, as plantas, os frutos, as sementes, as raízes, as gomas, etc., totalmente desconhecidos antes dos Descobrimentos Ibéricos.

Sendo mais antigo o conhecimento das espécies animais do que o dos vegetais, é com a descoberta do caminho marítimo para a Índia e com a subsequente exploração de novos territórios, que uma verdadeira ressurreição das Ciências biológicas, as quais pouco ou nada progrediam desde os Gregos, se vai produzir.

No domínio da Botânica são os «Colloquios dos simples e drogas medicinaes» (1563) de Garcia d'Orta, que fazem época nessa ciência, o mesmo sucedendo com a terapêutica, pois que a sua obra revelou o uso dos simples e das drogas vegetais para o tratamento de doenças desconhecidas no sistema médico de Galeno. A sua obra revelou ao mundo a botânica e a farmacologia das misteriosas regióes do Oriente, e conhecimentos que interessavam toda a Europa.

Plantas tão úteis na botica, como na cozinha e na higiene corporal, são inúmeras. 
Encontrando-se a costa do Brasil na metade atribuída a Portugal e sendo os jesuítas das pessoas mais cultas que visitaram o Brasil na época quinhentista, é nos seus escritos que encontramos os mais remotos dados sobre as maravilhas naturais do Novo Mundo. A disseminação mundial das plantas úteis deve-se aos portugueses e espanhóis. É o caso das laranjeiras, de origem asiática, introduzidas na América logo na primeira metade do século XVI, pelos portugueses e pelos espanhóis. A laranja de umbigo, ou da Baía, é descendente, por mutação, das laranjeiras que introduzimos no Brasil. Também a cana de açúcar foi introduzida no Brasil na primeira metade do século XVI, pois que se sabe que em 1518 os portugueses tinham muitos engenhos no Brasil. Por sua vez o trigo, principal cereal do Ocidente, teria sido introduzido no Novo Mundo pelos espanhóis cerca do ano de 1520. No capítulo alimentar foram missionários que introduziram na Capitania do Pará a couve marciana, a lombarda, a galega, e os pepinos. Ao primeiro que cultivou alface «appelidarão» o "alfacinha»

Já o cronista Pêro Vaz de Caminha, o qual seguia na Armada descobridora do Brasil, no ano de 1500, como escrivão, dizia em carta a D. Manuel ser a terra graciosa que aproveitada, dar-se-á nela tudo, mas então sem outro préstimo, além de aguada no caminho das Índias. Nos nossos dias, é o historiador Oliveira Marques, que diz «Não concebemos o mundo de hoje sem os Descobrimentos, sem o café, o cacau, o tabaco, as drogas, tudo o que faz parte da civilização quotidiana».

Foi um português, o sargento-mór Francisco de Melo Palheta que levou sementes de café para o Brasil em 1727. Em fins do século XVIII ainda o café era considerado um medicamento na cidade de S. Paulo, vendendo-se nas farmácias.

Também o cacaoeiro (Theobroma cacao L.) é de origem americana. Cacau e chocolate são palavras de origem asteca, tendo sido o conquistador Fernando Cortêz o primeiro que enviou para a corte de Carlos V de Espanha sementes de cacau com as instruçóes para preparar o chocolate. Ao cacau também se atribuem malefícios. É Madame de Sévigné que assevera ter certa dama tomado tanto chocolate durante a gravidez, que dera à luz uma criança " preta como o diabo»!

Que dizer do tabaco (Nicotiana tabacum L.), oriundo da América, e sem o qual o que seria o quotidiano de muitos ocidentais? Teria sido, segundo Damião de Góis, introduzido na Europa pelos portugueses, desde 1500: «esta erva trouxe primeiramente a Portugal Luis de Goês». E foi cerca do ano de 1500 que João Nicot, embaixador de França em Lisboa, «recebeu um dia, de um dos guardas do jardim do Rei esta herva florida que levou para um jardim onde ela cresceu e se multiplicou abundantemente». Estes exemplares, de origem brasílica, cultivados no Horto Real, foram mandados para França, pois Nicot verificara as suas propriedades curativas apreciadas por nós portugueses. Daí o seu nome de «erva santa»

João Nicot enviou a Catarina de Médicis pó de tabaco destinado a curar as enxaquecas da rainha. Era fármaco de que se usou e abusou, a pontos de em França ter sido proibido por Luis XIII a sua venda e o Papa Urbano VIII excomungar os fumadores. Mas face à inutilidade de tais persecuções, os governos conformaram-se e dela fizeram uma fonte de rendimentos, decretando Colbert, em França, o seu monopólio desde 1674 e em Portugal o mesmo sucedeu até 1781. Note-se que esta planta não só já era fumada pelos índios no decurso das suas cerimónias como também aplicavam o seu fumo para tratamento de feridas. De qualquer forma Nicot apenas se limitou a introduzir a planta em França, porque o tabaco já se usava em Espanha e Portugal, muitos anos 
antes. O desenvolvimento da Botânica, e consequentemente da Agricultura foi uma das Heranças dos Descobrimentos, pois que os exploradores e navegadores levaram para os seus países de origem amostras da flora das regiōes descobertas.

No domínio da alimentação, citaremos a batata e o milho.

A Batata (Solanum tuberosum Li), originária dos Andes, na América do Sul, foi introduzida na Europa no fim do século XVI. Este legume apenas se tornou alimento de base em fins do século XVIII, tendo-se tornado o legume mais universalmente disseminado no mundo. A batateira constitui com o milho um dos presentes do Novo ao Antigo Continente. A introdução da batata marcou para a Europa uma data fundamental na luta contra a desnutrição crónica das populações. Parece que a batateira só pode ter sido introduzida na Europa pelas costas atlânticas da América, onde chegou após o estabelecimento das comunicações terrestres, atravessando o continente americano. $\mathrm{O}$ país que a recebeu foi a Espanha apontando-se 1565 como data provável. De Espanha os frades carmelitas levaram-na para Itália.

A favor da origem americana da batata, há o facto de figurar entre os produtos oferecidos por Cristóvão Colombo à Rainha Isabel.

Também o milho (Zea mays), cujo cultivo, no Novo Mundo, constituía a base alimentar das civilizações précolombianas, sendo largamente cultivado pelos indios, só foi conhecido e difundido na Europa, e mais tarde em África e na Ásia, depois das grandes viagens das Descobertas, concretamente depois da descoberta da América. Tendo sido cultivado em Portugal ou talvez antes, no século XVI. Ainda no século XVI os portugueses foram responsáveis pela introdução da cultura na costa ocidental de África e posteriormente introduziram-no na Índia e na China. No Congo os indígenas chamavam ao milho, em fins do século XVI, grão de Portugal. Contudo deve-se a Cristóvão Colombo a introdução da planta na Europa. Foi cultivada como ornamental em Espanha (Cádiz) e daí passou para a Europa e Itália, via Sicília. Os Espanhóis, que primeiro que nós o devem ter conhecido, não o cultivaram como alimento senão mais tarde, por recearem os seus efeitos. De entre os legumes que alteraram os hábitos alimentares do Velho Mundo citaremos ainda o feijão (Phaseolus $s p p$.), o tomate, o pimento, e outros «viajantes» como o girassol e o amendoim. De entre os frutos «viajantes», além do ananaz, citaremos a pêra abacate, a anona ou fruta do Conde, a manga, o maracujá, a banana, a papaia, e acima de todos, os citrinos Esta palavra citrino designa colectivamente os frutos das diversas espécies do género. Com a excepção da toranja e da lima, limetta, pensa-se em geral que os citrinos são todos originários da China e da Ásia do Sudoeste. Com os navegadores portugueses e espanhois inicia-se a sua disseminação por várias regiões da América.

Se a laranjeira (Citrus sinensis L.) e (Citrus aurantium L.) é de origem asiática, ela foi porém introduzida em Portugal na época dos Descobrimentos em fins do século XV, com a viagem de Vasco da Gama. A primeira laranjeira da China que se plantou em Portugal em Lisboa, trouxe-a D. Franscisco de Mascarenhas, em 1635, da China a Goa e da Índia para o seu jardim em Xabregas. No século XVI a sua cultura generalizou-se não só em Portugal como em todos os seus domínios coloniais, incluindo o Brasil.

Mas nem só de "pão vive o homem» e com os Descobrimentos novos motivos de beleza surgem, com a introdução e disseminação de animais, flores e plantas ornamentais. Era de Portugal que saíam para delícia e recreação de outros europeus, «muitos buzios de diversas feições e papagaios de lindas cores e grandes habilidades, e outros animais raros». 
De entre as plantas ornamentais, citaremos o tabaco, pois que foi primeiro cultivado como planta decorativa, o mesmo sucedendo com as laranjeiras, que revolucionaram a arquitectura dos jardins. $\mathrm{O}$ mesmo quanto ao girassol, ao Arachis, e às palmeiras. Mesmo a Baunilha que não produzia frutos fora do seu país de origem, o México, permaneceu durante muito tempo como planta ornamental. O Aloês (Aloe variagata), originário do Cabo da Boa Esperança e introduzido no Velho Mundo, não pela beleza das suas flores vermelhas e elegantes, mas sim pela beleza da sua folhagem. Hoje abunda como planta decorativa em todos os jardins.

Outras plantas universalmente conhecidas como plantas decorativas são as Begónias sendo o Brasil a pátria da Begónia semperflorens, enquanto que o Perú, a Bolívia e o México forneceram outras espécies.

A Cana da Índia (Canna indica L), originária da América tropical e da Índia Ocidental, de há muito cultivada nas regióes mais quentes da Europa como ornamental, em canteiros e bordaduras, devido à beleza e ao vivo colorido das suas grandes flores. Já no século XVI Clusius dá uma descrição da planta, afirmando que a viu bastante frequentemente cultivada em Portugal junto às paredes dos mosteiros onde florescia a meio do verão. Clusius acrescenta ainda que os espanhóis e portugueses a designavam por cuentas (contas), pois que faziam rosários com as suas sementes.

As Chagas (Tropaeolum majus), originárias do Perú e da Columbia eram antigamente consumidas sob o nome de "agrião da Índia», comendo-se as folhas e outras partes da planta em salada: os botôes florais e os frutos eram conservados em vinagre, e usados como condimento semelhante às alcaparras

Citaremos ainda tantas e tantas outras flores, como os Cosmos, o Cravo da Índia, as Dálias, de origem mexicana; os Gladíolos e as Strelitzia, (Aves do Paraíso), da África do Sul, e dentre essas tantas outras uma se destaca: os gerânios, sardinheiras ou pelargónios (Pelargonium), nome comum «gerânio», cultivado a partir das espécies selvagens da África do Sul. Numerosas e belas variedades foram criadas, contandose esta flor entre as mais apreciadas tanto como planta de interior como de jardins, sacadas, varandas, janelas e vasos.

Contudo não foi apenas nos domínios científicos e de disseminação de plantas úteis ou decorativas que se reflectiram as navegaçōes Ibéricas da $2^{\text {a }}$ metade do século $\mathrm{XV}$, mas em todas as fases da vida quotidiana europeia: na higiene corporal, com o uso de perfumes, na do vestuário, com o advento do algodão, e na gastronomia, com o uso das especiarias.

A própria literatura substituiu as antigas lendas e os romances de cavalaria por relatos de viagens e aventuras em países longínquos e até então inacessíveis.

O Tratado de Tordesilhas (1494), dividindo o mundo ainda por descobrir, entre Espanha e Portugal, apesar da divisão geográfica, tornou portugueses e espanhóis responsáveis por uma "aculturação" da própria Natureza, com a dissiminação e troca de plantas e sementes realizadas a partir do século XVI, irmanando-os na busca da Ciência e da Beleza as quais não conhecem fronteiras. 


\section{BIBLIOGRAFIA}

Albuquerque, Luís de, As Navegações e a sua Projecção na Ciência e na Cultura, Lisboa, Ed. Gradiva, 1987.

ANCHIETA, José d', Carta de 1585, Informações e fragmentos históricos do P. José d'Anchieta, S. J., Rio de Janeiro, Imprensa Nacional, 1886.

BARros, João de, Ásia. Dos feitos que os Portugueses fizeram no descobrimento e conquista dos mares e terras do Oriente, 4 vols., Lisboa, Ed. Henâni Cidade, 1945-1946.

CunHA, Fanny A. Font Xavier da - Viagens e viajantes científicos. Sobre a flora exótica farmacêutica e alimentar lusíada, Actas Congresso Internacional Bartolomeu Dias e a sua Época. Vol. II, Universidade do Porto/ Comissão Nacional para as Comemorações dos Descobrimentos Portugueses, Porto, pp. 483-503.

FrançA, Carlos - Os portugueses do século XVI e a História Natural do Brasil, Sep. da Revista de História, vol. XV, Lisboa, 1928.

FrançA, Carlos - Subsídios para a história de algumas plantas cultivadas, Porto, ed. Araújo \& Sobrinho, Março de 1928. Col. «Natura».

GALVĀO, António - Tratado dos vários e diversos caminhos, por onde nos tempos passados a pimenta e a especiaria veio da Índia às nossas partes. .., Lisboa, 1563 e 1731; ed., Porto 1744.

Gandavo, Pero de Magalhães - História da Provincia de Santa Cruz a que vulgarmente chamam Brasil,

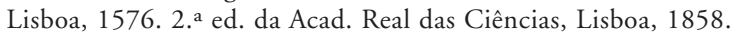

Nóbrega, Padre Manuel da - Cartas do Brasil e Mais Escritos do Pe Manuel da Nóbrega (Opera Omnia) Int. Notas Históricas e Críticas de Serafim Leite, Coimbra, Por Ordem da Universidade, 1955.

ORTA, Garcia d', Coloquios dos simples e drogas e cousas medicinais da India, Lisboa., ed. fac-similada da Academia das Ciências, 1963.

SOUSA, Gabriel Soares de, Notícia do Brasil (MS 1587), Impr: Ac. Real Sc. de Lisboa, 1825. Coment. e notas por Varnhagen, Pirujá da Silva e Edelweirs, Ed. C. Falcão, São Paulo, Brasil, Col. «Brasiliensia Documenta", 7, 1974. 


\section{Colecçãa \\ 2 Ciências e Culturas Caimbra 2006}

